\title{
LETTER TO THE EDITOR (JUV 28, 2017) CONCERNING THE PAPER "MORTALITY FOR CHRONIC-DEGENERATIVE DISEASES IN TUSCANY: ECOLOGICAL STUDY COMPARING NEIGHBORING AREAS WITH SUBSTANTIAL DIFFERENCES IN ENVIRONMENTAL POLLUTION"
}

Dear Editor,

Marabotti et al. have recently published an ecological study on mortality for chronic-degenerative diseases in the Tuscan area [1]. As we are operating the Tuscan Regional Mortality Registry, the Tuscan Cancer Registry and the Tuscan Mesothelioma Registry at the Cancer Research and Prevention Institute (Istituto per lo Studio e la Prevenzione Oncologica - ISPO), it is necessary to send a few considerations and questions regarding the study design and the health data presented in the paper.

First of all, the second aim declared in the paper is hardly achievable with the ecological study as that one presented, although we recognize the importance to take into consideration all available health data in areas characterized by environmental problems as recently made by SENTIERI (Studio Epidemiologico Nazionale dei Territori e degli Insediamenti Esposti a Rischio da Inquinamento - Epidemiological Study of Residents in National Priority Contaminated Site) Project in Italy using a descriptive study design [2-4].

In the Table 1 it appears clearly that the authors presented mortality rates and not standardized mortality ratios (SMRs) because they declare to present "death/100 000 population $\times$ year." Standardized mortality ratios are ratios between observed and expected deaths, and therefore the value for the reference population must be equal to 1 . Using the same causes of death for the same population and period considered by the authors we calculated the SMRs, and none of them was so high as it appears in the Table 1 of Marabotti et al.'s paper, as you can observe in the Table 1 of this letter, where the statistical significant excesses are reported in bold. Furthermore, the data is not reported per year but it is the mean value for the whole period under consideration (2001-2010) as mentioned in the title of the Table 1.

The authors write in the Material and Methods that "Mortality rates for the years 2001 to 2010 were obtained by files elaborated by the Institute for Oncological Study and Prevention (Istituto per lo Studio e la Prevenzione Oncologica - ISPO) [...]." At the ISPO we are used to elaborate mortality rates but we did not elaborate the reported data. For a few years we have generally used the European standard population published by Eurostat in 2013 as standard population [5]. Which is the standard population used by the authors to calculate the standardized mortality rates presented in the Table 1 ? 


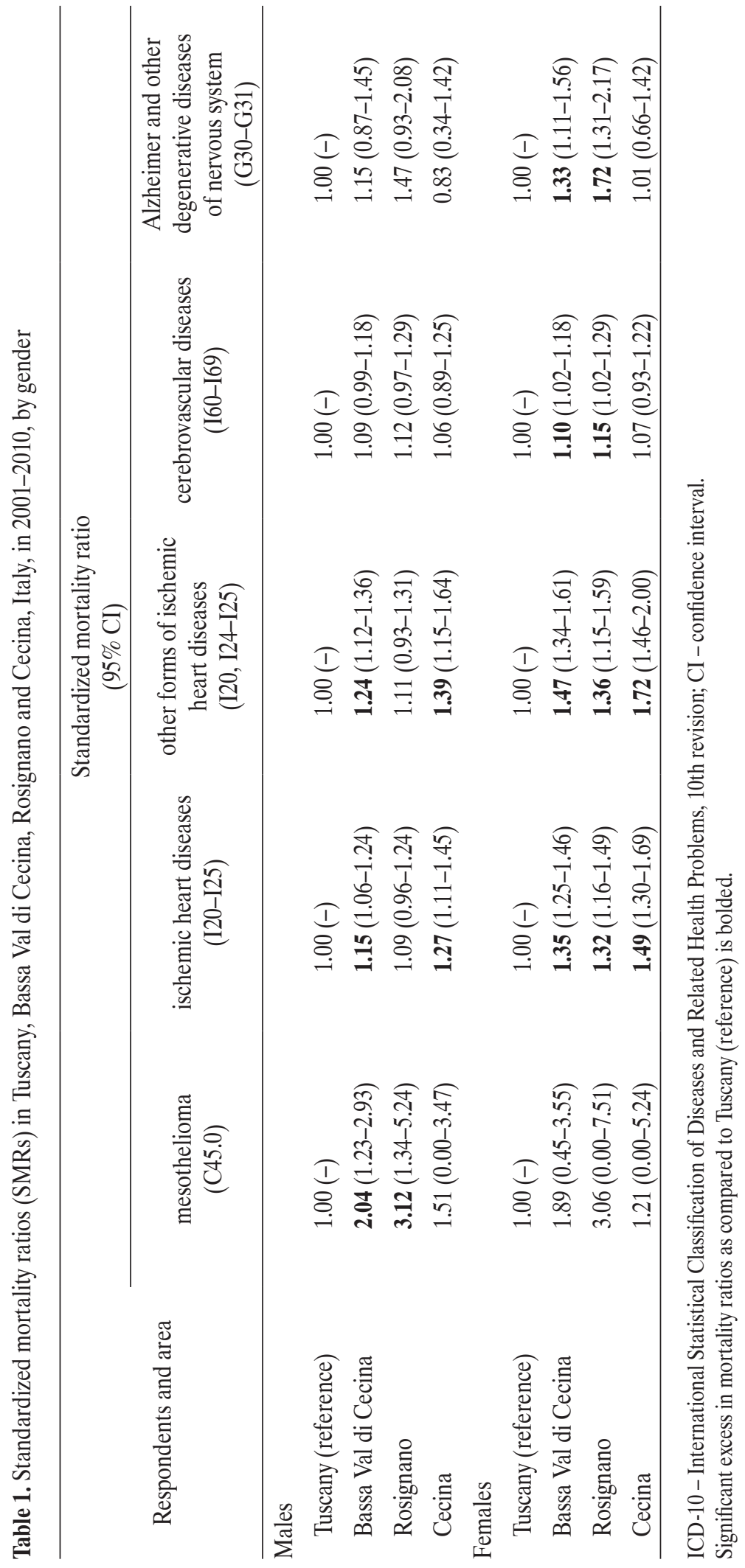


There is also probably a mistake reported in the same Table 1: the value of mortality rate for cerebrovascular diseases among Tuscan males is equal to the one reported for ischemic heart diseases among Tuscan males, that equals $95 \%$ confidence interval (CI); according to our knowledge it would have been lower.

The causes of death are reported in the International Statistical Classification of Diseases and Related Health Problems, 10th revision (ICD-10) version:

- it seems that the authors wanted to evaluate all ischemic heart diseases and all of them excluding acute ischemic heart diseases; if this is a correct interpretation they would have had to exclude causes of death coded with I22 from the group of "other forms of ischemic heart disease" (the third column of data) because I22 is the code used for other acute ischemic forms;

- with ICD-10 version the rules of coding have been changed and it would be better to evaluate Alzheimer diseases with other dementia, as the National Institute of Statistics does, considering together the codes G30, F01 and F03 [6];

- the new ICD-10 version had an impact also on coding mesothelioma deaths; the code C45 allows to identify all malignant mesotheliomas of all topographic sites; which data have the authors considered in the analysis? In the Material and Methods the authors refer to data on other causes of death but the data is not reported in the paper, meanwhile the evaluation of other causes of death with a relevant etiological fraction related to environmental problems would be of interest. It must be taken into consideration that in Italy the global burden of causes of death attributable to environment is only $1.6 \%$ [7].

Cardiovascular diseases are the first causes of death in all high income countries, Italy included. For these last causes the availability of efficient medical and surgical treatments and emergency procedures have a high impact and this must be considered when we want to evaluate the impact of environmental problems on these causes.
The authors also refer to have used the $\mathrm{Chi}^{2}$ test for comparing rates, and at the same time they present $95 \%$ CIs for each reported rate: $95 \%$ CIs are sufficient to judge if there is difference between 2 areas evaluating their overlapping. Which is the reason to use the $\mathrm{Chi}^{2}$ test as well as $95 \% \mathrm{CI}$ ?

Another consideration regards what the authors mentioned almost at the end of the Discussion. They write "A careful investigation of each case of mesothelioma, to identify the possible cases arising in subjects with no professional exposure to asbestos, seems thus strongly advised." It must be stressed that a specific surveillance system on malignant mesotheliomas has been active in Tuscany since 1988 and it has been in force in Italy since 2003. The Cancer Research and Prevention Institute is also responsible for the activity of the Tuscan mesothelioma register and each case is deeply investigated in cooperation with the local Occupational Public Health Services. Until now several papers have been published on them as well as on cases not occupationally exposed [8-12].

\section{Key words:}

Ecological study, Mortality, Environmental health, Ischemic heart disease, Mesothelioma, Standardized mortality rate

\section{REFERENCES}

1. Marabotti C, Piaggi P, Scarsi P, Venturini E, Cecchi R, Pingitore A. Mortality for chronic-degenerative diseases in Tuscany: Ecological study comparing neighboring areas with substantial differences in environmental pollution. Int J Occup Med Environ Health. 2017;30(4):641-53, https://doi. org/10.13075/ijomeh.1896.00972.

2. Pirastu R., Iavarone I, Pasetto R, Zona A, Comba P, editors. [SENTIERI Project - Mortality study of residents in Italian polluted sites: Results]. Epidemiol Prev. 2011;35(5-6) Suppl 4:1-204.

3. Pirastu R, Comba P, Conti S, Iavarone I, Fazzo L, Pasetto R, et al., editors. [SENTIERI KIDS - Mortality, cancer incidence and hospital discharges Epidemiological study of 
residents in national priority contaminated sites: Incidence of mesothelioma]. Epidemiol Prev. 2014;38(2) Suppl 1:1-170.

4. GdL SENTIERI-ReNaM. [SENTIERI - Epidemiological study of residents in national priority contaminated sites: Incidence of mesothelioma]. Epidemiol Prev. 2016;40(5) Suppl 1:1-116.

5. European Commission. Revision of the European standard population - Report of Eurostat's task force [Internet]. Luxembourg: Publications Office of the European Union, 2013 [cited 2017 Jul 15]. Available from: http://ec.europa.eu/eurostat/documents/3859598/5926869/KS-RA-13-028-EN.PDF/ e713fa79-1add-44e8-b23d-5e8fa09b3f8f.

6. Italian National Institute of Statistics [Internet]. Rome: The Institute; 2017 [cited 2017 Jul 15]. [Trends of cause-specific mortality: The 25 leading causes]. Available from: http://www. istat.it/it/files/2017/05/Report-cause-di-morte-2003-14.pdf?title $=\mathrm{L} \% \mathrm{E} 2 \% 80 \% 99$ evoluzione + della + mortalit $\% \mathrm{C} 3 \% \mathrm{~A}$ $0+$ per+causa+-+04\%2Fmag $\% 2 \mathrm{~F} 2017+-+$ Testo+integrale $+\mathrm{e}+$ nota + metodologica.pdf. Italian

7. Institute for Health Metrics and Evaluation. GBD Compare [Internet]. Seattle: The Institute 2017 [updated 2017; cited 2017 Jul 15]. Available from: http://www.healthdata.org/ data-visualization/gbd-compare.

8. Istituto per lo Studio e la Prevenzione Oncologica [Internet]. Firenze: The Institue [cited 2017 Jul 15] [Regional Operational Centre on mesothelioma of Tuscany]. Available from: http://rtrt.ispo.toscana.it/artmm/Biblio.html. Italian.

9. Istituto Nazionale per l'Assicurazione contro gli Infortuni sul Lavoro [Internet]. Rome: The Institue; 2016 [cited 2017 Jul 15]. [Mesothelioma National Registry]. Available from: https://www.inail.it/cs/internet/attivita/ricerca-e-tecnologia/ area-salute-sul-lavoro/sorveglianza-epidemiologica-negliambienti-di-lavoro-e-di-vita/renam.html. Italian.
10. Chellini E, Martini A, Cacciarini V, Badiali AM; Referenti delle Aziende sanitarie locali toscane. [Considerations about the epidemiologic surveillance system on mesothelioma in Tuscany (Italy) after 25 years of activity]. Epidemiol Prev. 2013;37(1):43-50. Italian.

11. Corfiati M, Scarselli A, Binazzi A, Di Marzio D, Verardo $\mathrm{M}$, Mirabelli $\mathrm{D}$, et al. Epidemiological patterns of asbestos exposure and spatial clusters of incident cases of malignant mesothelioma from the Italian national registry. BMC Cancer. 2015;15(1):286, https://doi.org/10.1186/ s12885-015-1301-2.

12. Marinaccio A, Binazzi A, Bonafede M, Corfiati M, Di Marzio D, Scarselli A, et al. Malignant mesothelioma due to non-occupational asbestos exposure from the Italian national surveillance system (ReNaM): epidemiology and public health issues. Occup Environ Med. 2015;72(9):648-55, https://doi.org/10.1136/oemed-2014-102297.

Elisabetta Chellini ${ }^{1}$, Andrea Martini ${ }^{1}$, Lucia Giovannetti ${ }^{1}$, and Alessandro Barchielli ${ }^{2}$

Cancer Research and Prevention Institute (ISPO), Florence, Italy

${ }^{1}$ Unit of Occupational and Environmental Epidemiology ${ }^{2}$ Cancer Registry Unit

Corresponding author: Elisabetta Chellini Cancer Research and Prevention Institute (ISPO) Unit of Occupational and Environmental Epidemiology via delle Oblate, 2, I - 50141 Florence, Italy (e-mail: e.chellini@ispo.toscana.it)

This work is available in Open Access model and licensed under a Creative Commons Attribution-NonCommercial 3.0 Poland License - http://creativecommons.org/ licenses/by-nc/3.0/pl/deed.en. 